\title{
Digital technologies and higher education in Russia: new tools of development
}

\author{
Tatiana Dmitrieva ${ }^{1 *}$, Elena German $^{2}$, and Tatiana Khvatova ${ }^{1}$ \\ ${ }^{1}$ Peter the Great St. Petersburg Polytechnic University, Institute of Industrial Management, \\ Economics and Trade, International College of Management, 195251, Politechnicheskaya st., 29, \\ Russian Federation \\ ${ }^{2}$ Peter the Great St. Petersburg Polytechnic University, Institute of Computer Sciences and \\ Technologies, Higher School of Cyber-Physical Systems and Management, 195251, \\ Politechnicheskaya st., 29, Russian Federation
}

\begin{abstract}
The article gives consideration to the main trends of development of the system of higher education under conditions of economics digitization. The influence of technological revolution on the social sphere of society (education, employment) and public services has been analyzed. Characteristics have been given to the state and basic problems of development of higher education under conditions of digital economics; the main tasks and the ways of solving them in the area of focus: human resources and education of the program "Digital economics" have been enumerated. Consideration has been given to the project of the new network University of National Technical Initiative for training in professions associated with the use of advanced production technologies, intellectualization and robotization of production; its basic goals, objectives and specific features: short life cycle and network principle of functioning have been described. A concept of open educational resources - a modern social technology of training has been disclosed.
\end{abstract}

\section{Community digitization under conditions of technological revolution}

An explosive development at the turn of 21 century and propagation of new technologies, penetration thereof into all spheres of human activity bring about nowadays quick and deep changes of global markets, structure and character of the present-day industrial production, economics and social sphere. These changes get assessed as "technological revolution" based on the changeover from mass production of standardized produce to a flexible highperformance production manufacturing individualized produce. At that, the automation and robotization as well as intellectualization of production processes become the "flowthrough" manufacturing processes for all production types. Particularly these technologies shall provide a fundamentally different quality of economic growth.

\footnotetext{
*Corresponding author: DmitrievaTatAl@gmail.com
} 
Significant changes are expected in the nearest future in the labor market, especially in the traditional industries and occupations:

- change of labor market structure towards production facilities robotization will have consequences for employment in the segment of blue-collar occupations. According to forecasts the robots will replace to do jobs fulfilled by the people in $25-30 \%$ types of professional activity in the developed countries by 2035 [1];

- change of employment structure towards using artificial intellect will have consequences for "white-collar workers" - managers, analysts, and in some cases for top professional managers too. It is expected that up to $30 \%$ of corporate audit checks will be done by 2025 with the use of artificial-intellect technologies. Full robotization is possible in some segments of bank activity, business accounting, legal services, complex analytics [1];

- quick change of qualification requirements to employees make them change their attitude to professional career and selection of trades: the employees shall be ready and willing to establish work for themselves and take care of its economic efficiency;

- simultaneous formation of a demand for new occupations and trades in the labor market related to the use of advance production technologies, intellectualization, robotization of production.

The serious changes take place in the sphere of education, public health services, security and other services traditionally rendered by the state:

- practically all the spectrum of state services becomes electronic;

- monitoring of legally significant actions and financial operations begins to get implemented by means of intellectual robotized systems;

- a number of non-cash financial arrangements increases which is provided by the unlimited access to Internet;

- digital services in the social sphere related to real-time monitoring facilities (e.g., "smart" home, telemedicine) become more and more widely used;

- computer-aided education formats, including remote ones get developed. For instance, the digital educational platform Coursera declared in March 2016 that the number of its students had reached $18 \mathrm{mln}$., a number of passed courses had amounted to $3.6 \mathrm{mln}$., while a cumulative traffic of video reviews of courses had amounted to 17 thousand years. The number of students registered at edX platform reaches $7 \mathrm{mln}$. people. The Spanish massive open online courses (MOOC) platform Miriada X has attained a figure of 2 mln. students. All-India Counsel for Technical Education (AICTE) has decided that $10 \%$ of the curriculum in 10.8 thousand of technical institutions of the country are to be based on MOOC platform [1]. The number of students to pass the online courses shall amount to $11 \mathrm{mln}$. persons in Russia by 2026 [2].

The quality of services will rearrange itself in the sphere of education under conditions of technological revolution:

- professional education will encounter a growing competition on the part of nonacademic sphere. A changeover from a design-oriented education to the experimentaloriented one will take place. A transfer of practical skills will be provided not only through traineeships, but due to specifically established university laboratories too. The use of digital technologies in education will bring about the emergence of new methods of rendering educational services;

- the transformations will take place in science and scientific activity associated with the use of artificial intellect, "big data" and digitization of investigations. The full-scale experiments will be replaced with digital simulation; the use of digital means of information acquisition, processing and storage grows. 


\section{Convergence of education and economics of knowledge}

Improvement of educational system as the basis of the community social development and its economic growth is an important condition for the development of innovative economics.

The following trends are decisive at this stage of shaping the economics of knowledge:

- Education and training as the basis of the economics of knowledge.

- Creation and development of scientific potential - an important component of technological development.

- Process of convergence and integration of intradiscipline sciences.

- Building easy-to-access, prompt, portable, demanded sources of knowledge comparable with the biggest modern informational resources with respect to information volumes.

- Knowledge engineering (knowledge management).

- Promotion of automation into the sphere of knowledge production and rendering intellectual services [3, 4].

Development of higher education (HE) shall be oriented to increasing the quality of education and its accessibility, as well as training skilled personnel capable of quick integration into new labor markets, as well as continuously increase the level of their qualification and use knowledge, skills and competences acquired in the process of training.

The following basic directions are envisaged in the sphere of higher education in Russia, for example, in the framework of state program "Education development": modernization of structure of programs of higher education for providing flexibility and efficiency thereof; modernization of $\mathrm{HE}$ contents and technologies for providing compliance thereof with the requirements of modern economics and varying people's inquiries; forming a system of continuous education, which helps plot flexible (modular) trajectory of mastering new competencies; transformation of part of programs of secondary vocational education into programs of applied bachelor degree course; internationalization of Russian HE and expansion of export of Russian educational services.

In case of higher education modernization it is necessary to increase the quality of management and professional development of managers and qualification of scientific and pedagogical staff.

According to the forecasts of long-term social and economical development of the RF for a period up to 2030 developed by the Ministry of Economic Development and Trade of the Russian Federation the following results are expected [3]:

- specific weight of a number of students being educated in the leading HEI increases from $5 \%$ (2011) to $20 \%(2020)$;

- by 2020 the variation of number of students being educated according to the programs of higher education from a total number of students being educated according to the programs of vocational education will equal according to programs: applied bachelor degree course - $11 \%$, bachelor degree course - $40 \%$, specialists - $8 \%$, master's degree program - 10\%;

- specific weight of employed population that has passed the refresher training course and continuing education course at the age of 25-56 years will increase by 2020 from $2 \%$ to $55 \%$;

- specific weight of a number of students of HEI that have passed training abroad within academic year for at least 1 semester (except HEI of CIS) will increase from $0.1 \%$ (2011) to 6\% (2020);

- at least five Russian Universities will join the top hundred of the leading world Universities according to the world rating; 
- increase of a number of students up to $30 \%$ that get educated according to priority and capital-intensive directions, who will get education in HEI with big volume of contractual developments and investigations;

- increase of quantity of federal state HEI performing international recruiting of scientific and pedagogical personnel (during 5 years -15 pers.).

\section{Digital economics and education}

A concept of electronic economics has been articulated for the first time more than twenty years ago by Nicolas Negroponte, Head of UN Program "One Laptop Per Child". Later the concepts of Internet (or Web) economics have appeared; now a term Digital economics is used more frequently, which is understood as the economical activity, based on digital technologies.

The scientists of Tufts University conducted investigation in 2017 in cooperation with MasterCard Inc., in the framework of which a rating of 60 countries was compiled by the level of digital economics development [5]. At that, more than 170 indicators were used, e.g., availability of broadband network of mobile communication, laws on intellectual property, etc. As a result, Digital Evolution Index was assessed to indicate a proportion between demand and offer in the framework of digital economics, level of support on the part of the government and state institutions, rate of innovations development. In the course of investigation the countries were divided into four groups: "leaders", "promising", "with decelerating rate of growth" and "problematic".

Proceeding from investigation results, the leading countries featuring the most developed digital economies are as follows: Norway (broadband communication), Sweden (information technologies), Switzerland (technological development), Denmark (technological development), Finland (broadband communication), Singapore (technological development), South Korea (advanced technologies), Great Britain (technologies and innovations), Hong Kong (information technologies), USA (at that, many rural country regions have no broadband communication and suffer deficit of digital technologies), Australia, Canada, the Netherlands, New Zealand (Chairman of group Digital 5).

Russia has joined a rating of "promising" together with such countries as: China, Kenya, India, Malaysia, Philippines, Indonesia, Brazil, Columbia, Chile and Mexico. According to the report these are the countries possessing a "potential, which can help them occupy the leading positions" [6]. The following countries have been recognized as "problematic": SAR, Peru, Egypt, Greece and Pakistan.

According to calculations of BCG (Boston Consulting Group), Russia lags behind the leading countries approximately by 5-8 years [7]. Therefore, in order to increase the rate of digitization, it is necessary to actively develop the baseline technologies of a new pattern robotics technology, Internet of things, cloud services, additive production.

Russia has essentially advanced in the market of cloud services only, outpacing the markets of the leading countries with respect to the rate of development. There are certain barriers in the other spheres. For instance, the participants of the robotics technology market "are disturbed by the lack of personnel, insufficient experience of developments commercialization and high entry threshold alongside with weak competencies in marketing and industrial design according to investigation of the Russian venture company. The development of additive technologies is impeded by high dependence from the import equipment and consumption materials becoming more expensive, while in the sphere of Internet of things a slow response of the users is a hindrance" [8].

In August 2017 the Government of the Russian Federation approved the state program "Digital economics of the Russian Federation" designed up to 2024. The program has 
defined five basic directions of digital economics development: "regulatory control; personnel and education; forming investigation competencies and technical capacities; informational infrastructure; informational security" [9].

Giving consideration to the direction of personnel and education it is apparent that its tasks are as follows: "creating key conditions for training personnel of digital economics; improvement of education system, which shall provide the digital economics with competent personnel; establishment of the labor market, which is to be supported by the requirements of digital economics; building a system of motivation on mastering necessary competencies and participation of personnel in the development of digital economics of Russia" [9].

Director of Center on electrochemical energy storage and electric power systems of SkolTech, professor Keith Stevenson, staff expert of the Institute on the problems of digital generation reckons that the modern system of higher education is to be built on the principles of interdisciplinary and decentralization, which will result in the formation of a new system built according to an "apportioned" principle. The scientist underlines that an immediate access to any knowledge relevant at the age of information technologies is the main prerequisite for the establishment of information community aimed at receiving practical knowledge and skills, cross-cultural communication, self-learning capability and an ability to make several things simultaneously - multitasking [10].

In order to solve the main tasks of the direction "personnel and education", the investigation centers in the field of digital economics are being established in the leading Russian HEI. A National center of digital economics, which main task is the scientific and scientific-and-methodological support of digital economics in the RF as well as training of the respective personnel, has been established at Lomonosov Moscow State University. The Center has prepared proposals on establishing digital environment of the Eurasian Economic Union (EEU), conducting International conferences devoted to digital technologies.

The National Research University "Higher School of Economics" has presented a research and education project "Digital economics" to be implemented by the Department of world economics. The project has been established for the sake of studying: influence of the growing digitization of economics on the industrial, social, institutional and environmental aspects of economical activity in the world; development of digital transition in Russia and its integration into international environment of digital economics.

Bonch-Bruevich St. Petersburg State University of telecommunications as the leading industry HEI subject to general jurisdiction of the Federal Agency of Communication has taken an active part since September 2017 in establishing the centers of competence of "Digital economics" program in the direction "Investigations and developments".

\section{Network University of National Technical Initiative as a new approach to higher education development}

A project of the new network University of National Technical Initiative (NTI) on training specialists for work under conditions of digital economics and a concept of educational program of a new format oriented to professional development were introduced in SaintPetersburg in autumn 2017 in the framework of BarCamp" "National technological revolution 20.35".

\footnotetext{
${ }^{1}$ BarCamp - International network of conferences set up by its participants and takes place in the format of discussion sessions and presentations. The main topics are as follows: new media, social media, blogs, Web 2.0, startups, open-sources, etc.
} 
The Network University will be oriented to training leaders of the companies implementing a concept of national technological initiative and operating in the new global markets. Every trainee will get a chance to analyze the prospects of its career progress in a company as well as acquire necessary knowledge and experience. A profile of competences reflecting its real achievements and can be a guarantee of success in a particular role and in a particular project will be formed for every graduate instead of the diploma.

The leading HEI of the country will participate in NTI University "20.35": Moscow Institute of Physics and Technology, Peter the Great St. Petersburg Polytechnic University, Saint Petersburg National Research University of Information Technology, Mechanics and Optics, Novosibirsk State University, Tomsk State University, Far Eastern Federal University, as well as Federal Agency for Scientific Organizations, commercial companies. The work of the University will be intended for a short life cycle - since 2020 till 2035.

The key University's specific feature is the network principle of functioning with the use of capabilities of educational organizations and digital educational platforms, the best course and models of training, which are available in different HEI. The main task of the University is to build a platform by 2035, consisting of goal-oriented occupations, profiles and suppliers of competencies, which will help build a personal trajectory of trainee's development. At that, it is planned in the nearest ten years to train 10 thous. technological leaders, 100 thous. players of the new markets and 1 bln. digital profiles of competencies.

New social technologies of education, including open educational resources ${ }^{2}$ (OER) will be used in educative process at NTI University "20.35" [11]. Let us note that OER are actively developing and are being used at the federal and regional levels in Russia. They include: websites of HEI and subdivisions thereof, personal websites, websites of topical scientific and educational projects and systems of remote education, open electronic libraries of HEI, topical educational portals, Internet University of information technologies, educational video portal UniverTV.ru, portal "Unified window of access to educational resources" [12].

The recommendations of UNESCO Institute say that the "student organizations shall take an active part in providing OER quality in the framework of social media as well as it is necessary to encourage participation of students in measures aimed at supporting OER development" [13]. Taking it into account in the framework of BarCamp, the organizers have conducted a forum on the development of IT tasks on building new and refinement of the existing platforms for the network University. The presentation of NTI University "20.35" model has taken place at the forum and simultaneously hackathon ${ }^{3}$ has taken place in five Russian cities (Moscow, Saint-Petersburg, Vladivostok, Tomsk, Novosibirsk) "Gather University" that has gathered more than 1,000 participants - students, postgraduate students and young specialists.

The main task of hackathon was the establishment of services, applications, modules and platform solutions for NTI "20.35". As a result the participants of hackathon have prepared the following products: new types of digital educational content; smart systems of building individual trajectories of human-being development; artificial agents and digital counterparts; game characters accompanying the process of training; biometrical technologies of personal identification and assessing the trainee's state; virtual tutors; digital track analysis tools; competence profile management system. The issue of motivation and readiness of teachers to use new educational technologies is relevant for

\footnotetext{
${ }^{2}$ UNESCO Institute on information technologies has developed "Recommendations for cooperation with open educational resources in the sphere of higher education", which are designed for governmental structures, higher educational institutions, higher-education teaching personnel, student's organizations and establishments responsible for providing quality and accreditation [13].

${ }^{3}$ Hackathon - a forum of development agencies, when the experts from different fields of software development (software specialists, managers, designers) work jointly on solving a certain problem.
} 
Russian system of education. Thus, there exists a necessity of training teachers on the new educational technologies based on application of information and communications technologies. Let us note that an additional impetus for OER development in Russia is the enactment of the fourth generation educational standards envisaging application of new requirements and approaches to organization of educational process.

Today the world is on the brink of the next wave of innovations, which can seriously transform an established approach to education. The key changes will consist in the means of information transmission and storage, which makes education more approachable expanding the network of students all over the world. In this case, the academic activity will become more flexible and client-oriented, while a consumer of educational services will be able to shape the inquiries for receiving practical knowledge in the way convenient for it and within the shortest time possible.

\section{References}

1. V. N. Knyaginina. Expert and Analytical Report. 136 (2017)

2. Identification Document of Priority Project "Modern Digital Educational Environment in the Russian Federation". [online], Available at: http://static.government.ru/media/files/8SiLmMBgjAN89vZbUUtmuF51ZYfTvOAG.p $\underline{\mathrm{df}}(2016)$

3. Forecast of Long-term Social and Economical Development of the RF for a Period up to 2030 (the Ministry of Economic Development and Trade of the Russian Federation) [online], Available

at: http://economy.gov.ru/minec/activity/sections/macro/prognoz/doc20130325_06 (2013)

4. J. Lichy, M. Kachur, T. Khvatova, Journal of Marketing Management, 33 (9-10) (2017)

5. B. Chakravorti, R. S. Chaturvedi. Digital planet 2017. How competitiveness and trust in digital economies vary across the world. (The Fletcher School, Tufts University July 2017)

6. T. Kelly, A. Liaplina, S. Tan, H. Winkler. Reaping Digital Dividends: Leveraging the Internet for Development in Europe and Central Asia. Washington, DC. (World Bank, 2017)

7. B. Banke, V. Butenko, I. Kotov, et alii. Russia Online? It is not Possible to Catch up with. Falling Behind (Catching up with. It is not Possible to Fall Behind) (2017)

8. K. Kurkin, Expert Severo-Zapad. 9-11 (746) (2017)

9. Resolution of the Government of the Russian Federation" No.1632-p dated 28.07.2017. Program "Digital Economics of the Russian Federation" [online], Available at: http://static.government.ru/media/files/9gFM4FHj4PsB79I5v7yLVuPgu4bvR7M0.p df (2017)

10. L. Stein, Anthology Digital Economics. Skolkovo Foundation, 35-40 (2017)

11. A. V. Markeyeva. Economics. 8 (9) (2014)

12. A. Sigalov, A. Skuratov. Educational Portals and Open Educational Resources in the Russian Federation (2012) - [online], Available at: http://iite.unesco.org/pics/publications/en/files/3214704.pdf

13. Recommendations on Work with Open Educational Resources (OER) in the Sphere of Higher Education. UNESCO Institute on Information Technologies in Education. Education Association. (2011) 